Journal of Universal Language 3

September 2002, 57-74

\title{
A Comparison of Unish Grammar with Esperanto*
}

\author{
Dong-Young Lee
}

Sejong University

\begin{abstract}
The purpose of this paper lies in claiming that the grammar of Unish, which has been being developed at Sejong University, is simpler, more logical, and more regular in many aspects than that of Esperanto, which was created more than a century ago. The validity of this claim is checked by comparing Unish with Esperanto with regard to several main parts of grammar such as the formation of interrogative sentences and passive sentences, the system and use of personal pronouns and relative pronouns, the nonuse of expletives, and the non-occurrence of agreement in a noun phrase. On the basis of these comparisons this paper concludes that it is easier to learn and use Unish than Esperanto.
\end{abstract}

Keywords: universal language, Unish, Esperanto, comparison of grammars, principles of simplicity, logicality, regularity

I am deeply grateful to Myung-Gun Choo for the guideline of Unish grammar, constant encouragement, and insightful comments. Many thanks also go to Unish researchers (Tajima Akiko, Chul-Hyun Bae, Ki-Hyung Bae, Young-Hee Chung, Eun-Joo Kwak, Eun-Ju Noh, Hyun-Seok Park, and Jin-Young Tak) who made useful comments and creative suggestions. 


\section{Introduction}

As communication and trade between countries increase due to globalization, the need for a common language that can be easily acquired and used by all people in the world irrespective of their mother tongues also increases (Choo 1996, 2001; Hausser 2002; Kim 2001; Kim \& Read 1999; Large 1996, 2002). To satisfy the need to overcome a language barrier to free communication the Sejong University has been developing a new universal language called Unish (Choo et al 2000; Chung 1996, 2001; Diamond 1996) for several years.

The grammar of Unish is being constructed on the basis of the principles of simplicity, logicality, and regularity. We argue that Unish grammar based on these principles is easier to learn than the grammar of Esperanto (Comrie 1996, Esterhill 2002, Li 1991, Park 1989), which was created in the late nineteenth century. To support this argument we compare the grammar of Unish with that of Esperanto from various viewpoints. These viewpoints are based on easiness in forming interrogative sentences and passive sentences, consistency and regularity in personal pronouns, simplicity in relative pronouns, logicality in the use of content words instead of expletives, and simplicity arising from the non-occurrence of agreement in noun phrases.

\section{Comparison of Grammars in Esperanto and Unish}

\subsection{Interrogative Sentence}

In Esperanto, the basic word order of a sentence is a subject (S), a verb (V), and an object (O)/a complement(C). In an interrogative 
sentence a special word appears in the first position of the sentence. ${ }^{1}$
(1) a. Vi
ludas
la pianon.
you play-Pres the piano-Acc
"You play the piano."
b. $\hat{\mathrm{Cu}}$ vi ludas la pianon?
Intadv you play-Pres the piano-Acc
"Do you play the piano?"

As shown in (1), the placement of the word $\hat{C} u$ in front of a declarative sentence makes a yes-no-question.

In a wh-question, which is another type of an interrogative sentence, the word that corresponds to a wh-word in English (namely, who, when, where, what, why or how) must appear in the initial position as illustrated in (2).
(2) a. Kiam vi laboras? when you work-Pres "When do you work?"
b. Kiu li vizitis? who he visit-Pst "Who did he visit?"

Thus, a wh-question in Esperanto is very similar to that in English in that a wh-word appears in the initial position of a sentence.

1 The following abbreviations are used in the gloss:

Acc: accusative

Adjl: adjectival

Futr: future

Intadv: interrogative adverb

Pres: present

Psspref: passive prefix

Pssprg: passive and progressive
Actprg: active and progressive

Advsuf: adverbial suffix

Gen: genitive

Pl: plural

Prg: progressive

Pssprf: passive and perfect

Pst: past 
60 A Comparison of Unish Grammar with Esperanto

On the other hand, in Unish the word order of a sentence $(\mathrm{SVO} / \mathrm{C})$ is always kept regardless of a declarative sentence or an interrogative sentence.

$$
\begin{array}{lll}
\text { (3) a. De vered } & \text { tori. } \\
\text { you see-Pst } & \text { bird } \\
\text { "You saw a bird." } & \\
\text { b. De vered } & \text { tori? } \\
\text { you see-Pst } & \text { bird } \\
\text { "Did you see a bird?" }
\end{array}
$$

The word order of the two sentences in (3) is the same. The only difference between them is that (3a) ends with a period (.), whereas (3b) ends with a question mark (?).

Due to the fixed word order $(\mathrm{SVO} / \mathrm{C})$ in an Unish sentence, a wh-word appears in situ, in accordance with its function in a sentence, instead of moving to the front of a wh-question.

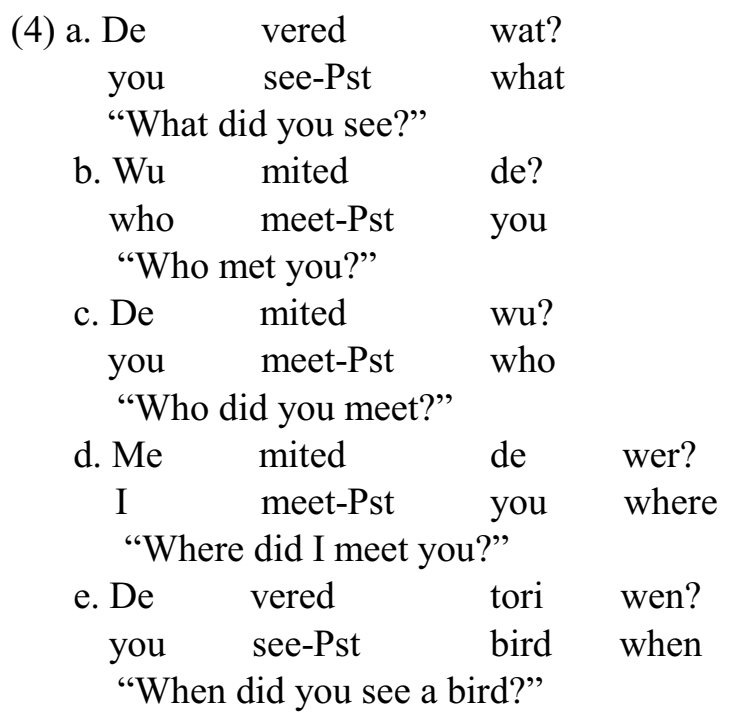




$\begin{array}{llll}\text { f. De mited } & \text { les } & \text { we? } \\ \text { you meet-Pst } & \text { they } & \text { why } \\ \text { "Why did you meet them?" } & \end{array}$

In sentence (4a), the word wat 'what' functions as an object and thus it appears after the verb vered 'saw'. The word $w u$ 'who' in sentence (4b) functions as a subject and thus it appears before the verb mited 'met'. Although the same word $w u$ is used in sentence (4c), it functions as an object and thus it appears after a verb. In sentence (4d) the word wer 'where' functions as an adverb and thus it appears after the pronoun de 'you', which functions as an object. Both the word wen 'when' in sentence (4e) and the word we 'why' in sentence (4f) also function as an adverb and thus they appear after an object.

Therefore, the only difference between a declarative sentence and an interrogative sentence in Unish is that the former ends with a period or a falling intonation, but the latter ends with a question mark or a rising intonation. The only thing to remember in making an interrogative sentence in Unish is the fixed word order (that is, $\mathrm{SVO} / \mathrm{C}$ ). In Esperanto, however, a special word must be placed in the initial position or a wh-word must be moved to the initial position in order to make an interrogative sentence. Accordingly, in Unish it is easier to learn and make an interrogative sentence to which both a yes-no-question and a wh-question belong than in Esperanto.

\subsection{Passive Sentence}

In Esperanto many suffixes are involved in making a passive sentence.

$\begin{array}{llll}\text { (5) a. Vi } & \text { verkis } & \text { la } & \text { libron. } \\ \text { you write-Pst } & \text { the } & \text { book-Acc } \\ \text { "You wrote the book." } & & \end{array}$


62 A Comparison of Unish Grammar with Esperanto

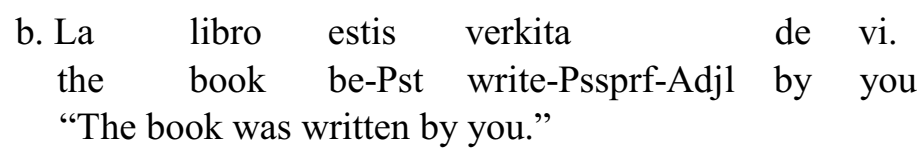

The sentence in $(5 b)$ is the passive counterpart of the active sentence in (5a). Since the tense of sentence (5a) is past, the suffix is, which indicates past tense, is attached to the verb est 'be' in (5b). In addition, the suffix it which indicates perfect aspect and the suffix $a$ which indicates adjectival function are attached to the main verb verk 'write' in (5b).

When the sentence in $(5 a)$ is changed into a sentence that has progressive aspect as shown in (6a), the suffix attached to the main verb of its passive sentence is also changed into at as illustrated in (6b).

(6) a. Vi estis verkanta la libron. you be-Pst write-Actprg-adjl the book-Acc "You were writing the book."

b. La libro estis verkata de vi. the book be-Pst write-Pssprg-adjl by you "The book was being written by you."

Depending on the voice and aspect of a sentence, the suffix attached to the main verb always varies in Esperanto. Nine suffixes (namely, int, ant, ont, it, at, ot, o, a, and $e$ ) are related to the form of a main verb in the process of constructing a passive sentence based on an active sentence.

In Unish, however, only one prefix is related to the form of a main verb in making a passive sentence, as illustrated in (7).

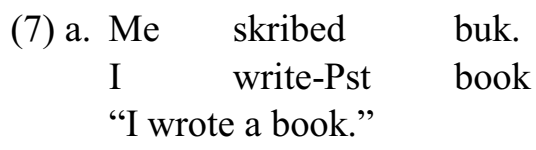


b. Buk beskribed be me. book Psspref-write-Pst by I

"The book was written by me."

c. Me esed skribing buk.

I be-Pst write-Prg book

"I was writing a book."

d. Buk esed beskribing be me. book be-Pst Psspref-write-Prg by I "A book was being written by me."

e. Me gived buk tu de. I give-Pst book to you "I gave you a book."

f. Buk begived tu de be me. book Psspref-give-Pst to you by I "A book was given to you by me."

g. Les esil giving buks tu de. they be-Futr give-Prg book-P1 to you "They will be giving you books."

h. Buks esil begiving tu de book-Pl be-Futr Psspref-give-Prg to you be les.

by they

"Books will be being given to you by them."

The sentences in $(7 b),(7 d),(7 f)$, and $(7 h)$ are the passive counterparts of (7a), (7c), (7e), and (7g), respectively. The only difference between an active sentence and its passive counterpart in the form of a main verb is that the prefix be is attached to the main verb in a passive sentence.

Therefore, it is much simpler and easier to make a passive sentence that corresponds to its active sentence in Unish than in Esperanto. 


\subsection{Personal Pronoun}

The system of personal pronouns in Esperanto is as illustrated in table (8).

(8) Personal Pronouns in Esperanto

\begin{tabular}{|c|c|c|c|}
\hline \multicolumn{2}{|c|}{ Person } & Singular & Plural \\
\hline \multicolumn{2}{|c|}{ First-Person } & $m i$ & $n i$ \\
\hline \multicolumn{2}{|c|}{ Second-Person } & $v i$ & $v i$ \\
\hline \multirow{3}{*}{$\begin{array}{l}\text { Third- } \\
\text { Person }\end{array}$} & Male & $l i$ & \multirow{3}{*}{ ili } \\
\hline & Female & $\hat{s i}$ & \\
\hline & Thing & $\hat{g} i$ & \\
\hline
\end{tabular}

The plural form of personal pronouns is not regular and the singular form of the third-person pronouns is classified into three categories.

On the other hand, the system of personal pronouns in Unish is regular, consistent, and simpler than that in Esperanto as shown in table (9).

(9) Personal Pronouns in Unish

\begin{tabular}{|l|l|l|}
\hline \multicolumn{1}{|c|}{ Person } & Singular & Plural \\
\hline First-Person & me & mes \\
\hline Second-Person & $d e$ & des \\
\hline Third-Person & le & les \\
\hline
\end{tabular}

Like the plural form of common nouns, a plural personal pronoun is obtained by attaching the suffix $s$ to a singular pronoun. Thus, the plural forms of all nouns are made just by attaching that suffix to their singular forms. There is only one third-person singular pronoun and thus the referent of that pronoun is determined based on the context in which it is used.

Accordingly, the total number of personal pronouns in Unish is 
smaller than that in Esperanto. In addition, the plural form of personal pronouns in Unish is regular, whereas that in Esperanto is irregular. Thus, it is easier to learn Unish pronouns than Esperanto ones.

\subsection{Relative Pronoun}

Depending on whether a relative pronoun functions as a pronoun or an adverb in a sentence, the relative pronoun to be used varies in Esperanto.

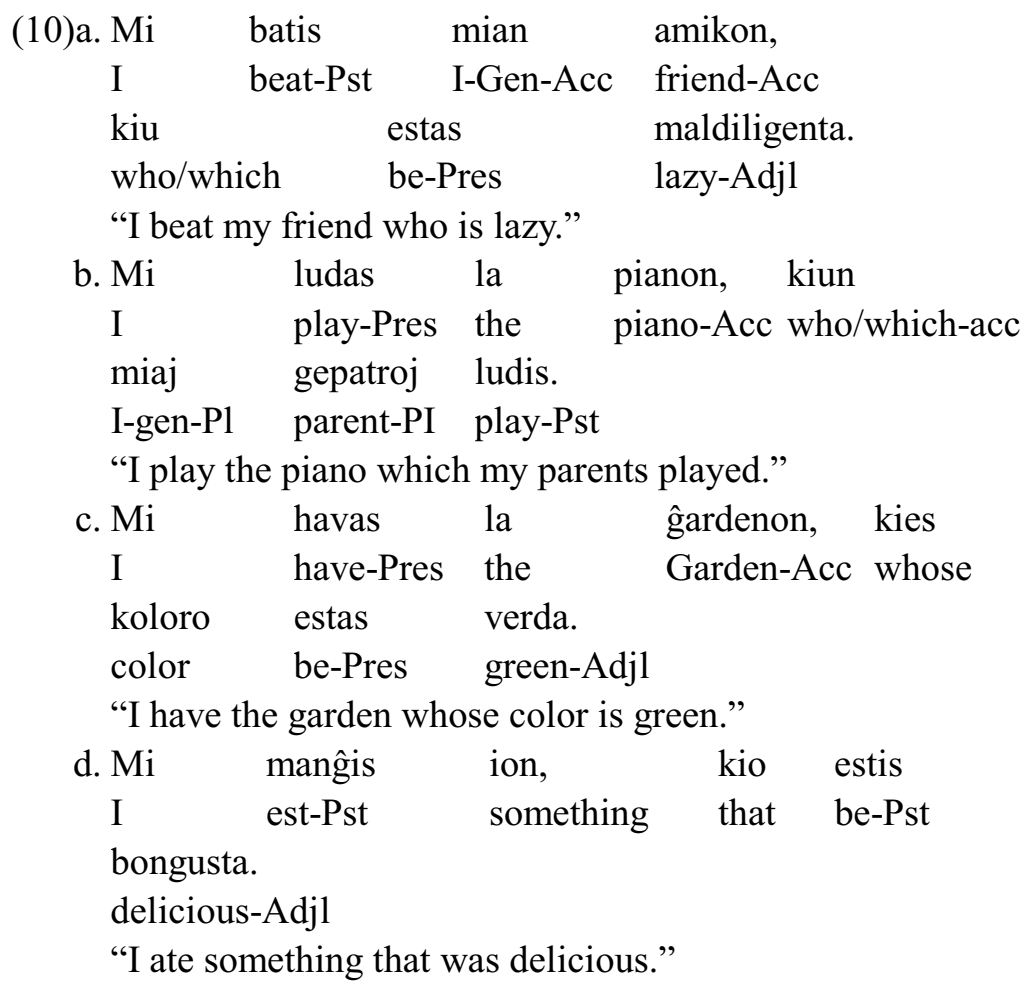


66 A Comparison of Unish Grammar with Esperanto

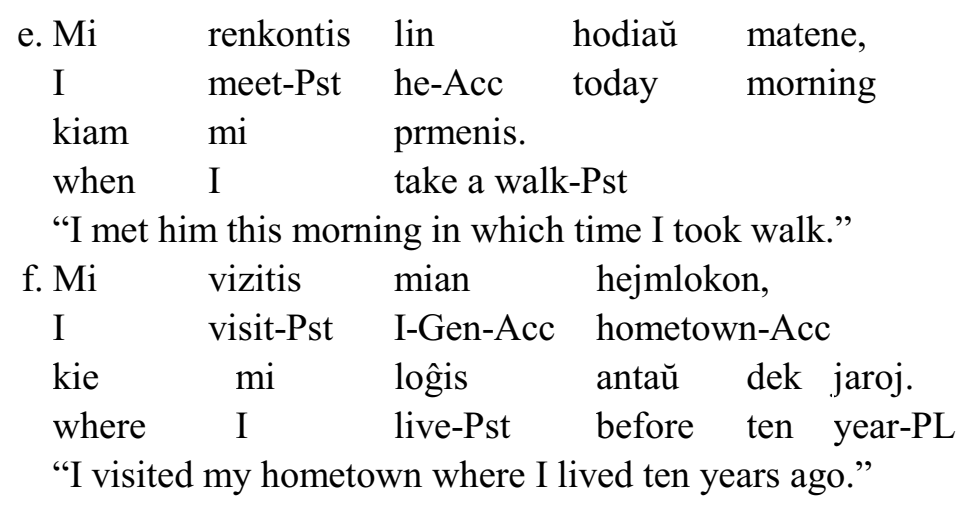

The relative pronouns kiu, kiun, kies, and kio appearing respectively in (10a-10d) function as a pronoun, whereas the relative pronouns kiam and kie occurring respectively in (10e) and (10f) function as an adverb. In addition, according to the case (namely, nominative, genitive, dative, and accusative) a relative pronoun takes, its form varies as shown in (10a-10c). For example, the relative pronoun kiu in (10a) takes nominative case, the relative pronoun kiun in (10b) takes accusative case, and the one kies in (10c) takes genitive case. Furthermore, when the head noun of a relative clause belongs to a special type as in (10d), a special relative pronoun kio is used.

On the other hand, in Unish only one relative pronoun (namely, $d a t$ ) is used irrespective of its function in a sentence.

(11) a. Les mited gens dat vered muze.
they meet-Pst people that see-Pst museum
"They met the people who saw the museum."
b. Me laik haus dat de
I vered.
"I like the house which you saw."
c. De lov haus dat's ruf me dezained
you love house that-Gen roof I design-Pst


"You love the house whose roof I designed."

d. Evriding dat beanonsed surprised les. everything that Psspref-announce-Pst surprise-Pst they "Everything that was announced surprised them."

e. Di dat de leved beremor. day that you leave-Pst Psspref-remember "The day when you left is remembered."

$\begin{array}{lllll}\text { f. Me lov kafe dat me mited } & \text { de. } \\ \text { I love café that I } & \text { meet-Pst you } \\ \text { "I love the cafe where I met you." } & & \end{array}$

Although the relative pronoun dat appearing in (11a-11d) functions as a pronoun, and the one dat occurring in (11e) and (11f) functions as an adverb, their form is the same. Except the occasion of genitive case the form of a relative pronoun is fixed regardless of the case it takes as illustrated in (11a) and (11b) (for example, the relative pronoun in (11a) takes nominative case, whereas the one in (11b) takes accusative case). Moreover, even when a special head noun of a relative clause occurs as in (11d), the form of a relative pronoun does not vary.

Therefore, the total number of relative pronouns in Unish is much smaller than that in Esperanto. This means that it is simpler and easier to learn the use and form of relative pronouns in Unish than in Esperanto.

\subsection{Expletive}

Expletives are not used in Esperanto. Instead, the subject of a sentence is totally omitted as shown in (12).
(12)
$\begin{array}{llllll}\text { Estas } & \text { la } & \text { dua } & \text { horo } & \text { kaj } & \text { dek } \\ \text { be-Pres } & \text { the } & \text { two-Adjl } & \text { hour } & \text { and } & \text { ten }\end{array}$ 
68 A Comparison of Unish Grammar with Esperanto

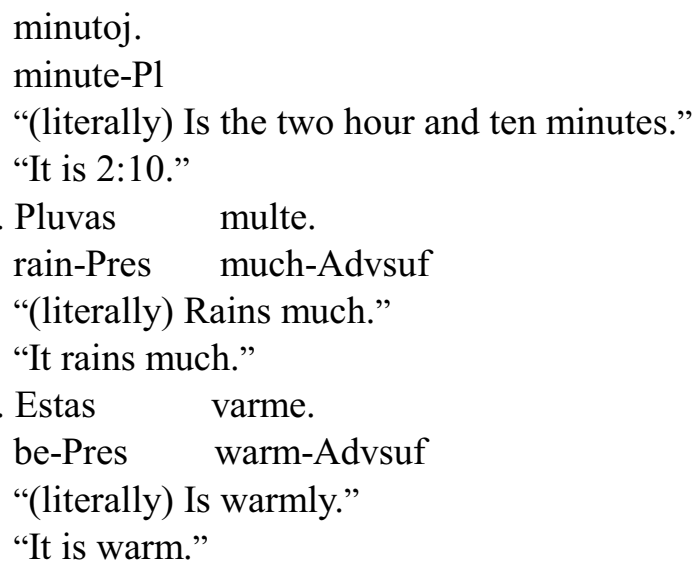

The sentence in (12a) is related to time, and the subject that indicates a point of time is missing. The sentence in $(12 \mathrm{~b})$ is related to natural phenomenon of raining, and only a verb and an adverb occurs in the sentence. Sentence $(12 \mathrm{c})$ is related to weather and the word varme in the sentence is strangely an adverb, not an adjective. This means that in a subject-less sentence the part of speech for the word which comes after the est-Verb must be adverb.

In Unish, however, instead of an expletive a meaningful content word is used as the subject of a sentence, as illustrated in (13).

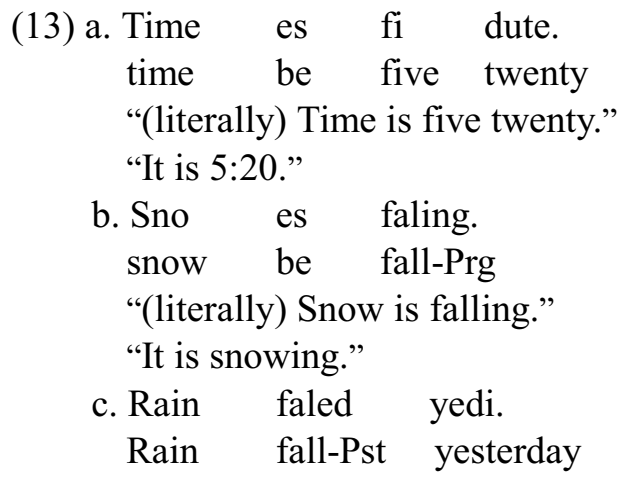


"(literally) Rain fell yesterday."

"It rained yesterday."

d. Weder es kul.

weather be cool

"(literally) Weather is cool."

"It is cool."

e. Weder esed nube yedi.

weather be-Pst cloudy yesterday

"(literally) Weather was cloudy yesterday."

"It was cloudy yesterday."

f. Wind blo todi.

wind blow today

"(literally) Wind blows today."

"It is windy today."

In (13a), the word related directly to time is explicitly used as a subject. In sentences (13b) and (13c) the real entity that falls from the sky is specified in a subject. In (13d) and (13e), the content word weder 'weather' is directly used as a subject in order to speak of weather. In sentence (13f), the actual entity that blows appears as the subject of the sentence.

Therefore, in both Esperanto and Unish the expletive that takes just the place of a subject is not used. In Unish, however, a content word is used as a subject and thus the meaning of a sentence is clearer and easier to be understood than that of a subject-less sentence in Esperanto.

\subsection{Agreement in Noun Phrase (NP)}

When an NP consists of a pronoun (or an adjective) and a noun, the former agrees with the latter in number (that is, singular or plu$\mathrm{ral}$ ) and case (for example, genitive or accusative). 
70 A Comparison of Unish Grammar with Esperanto

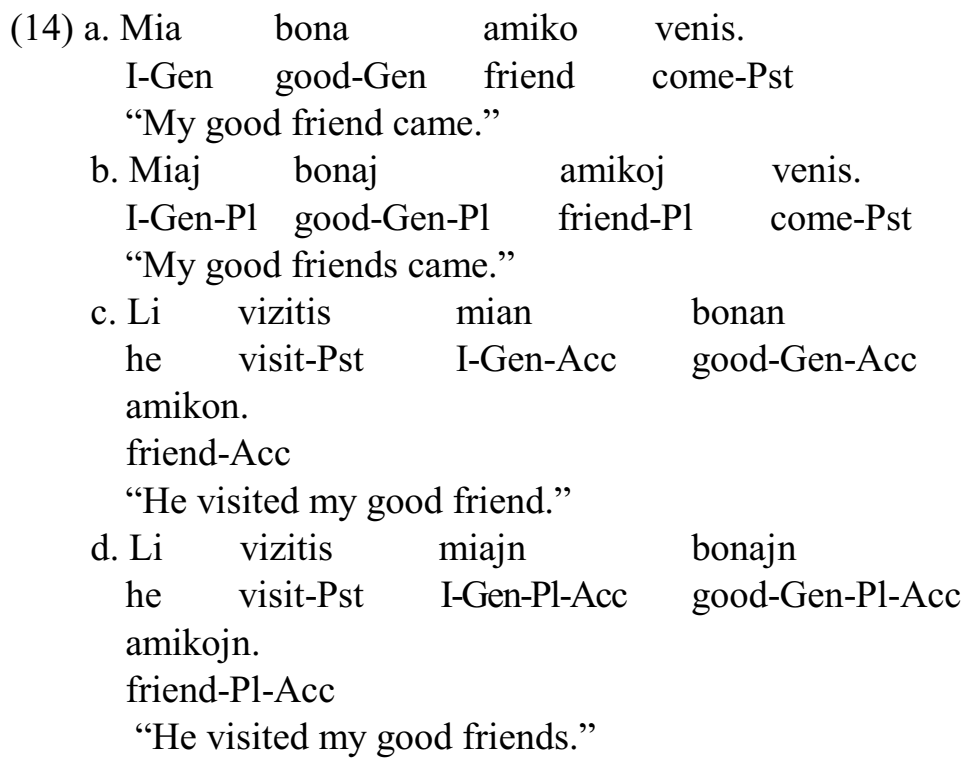

In Esperanto, the suffix for making a plural noun is $j$, and the suffix $a$ is attached to a noun (including a pronoun) or an adjective that modifies a noun. Thus, the suffix $a$ is attached to a word which is assigned genitive case. In addition, the suffix $n$ is attached to a noun whose case is accusative. But, no suffix is attached to a noun whose case is nominative.

In sentence (14a), the NP Mia bona amiko acts as a subject of the sentence and thus nominative case is assigned to it. Accordingly, no suffix is attached to the noun amiko in that NP. Since the pronoun $m i$ and the adjective bon modifies the following noun amiko, the suffix $a$ is attached to that pronoun and that adjective.

In (14b), the number of the noun amikoj is plural and thus the suffix $j$ is also attached to the pronoun and the adjective that precedes and modifies the noun.

The number and case of the noun amikon in the NP mian bonan amikon appearing in sentence (14c) is singular and accusative, re- 
spectively. Thus the suffix $n$ is attached to the pronoun and the adjective that precede the noun in that NP.

In (14d), the number and case of the noun amikojn is plural and accusative, respectively. Thus both the suffix $j$ and the suffix $n$ are attached to the pronoun and the adjective that precedes that noun.

On the other hand, the agreement in number and case does not occur in Unish.

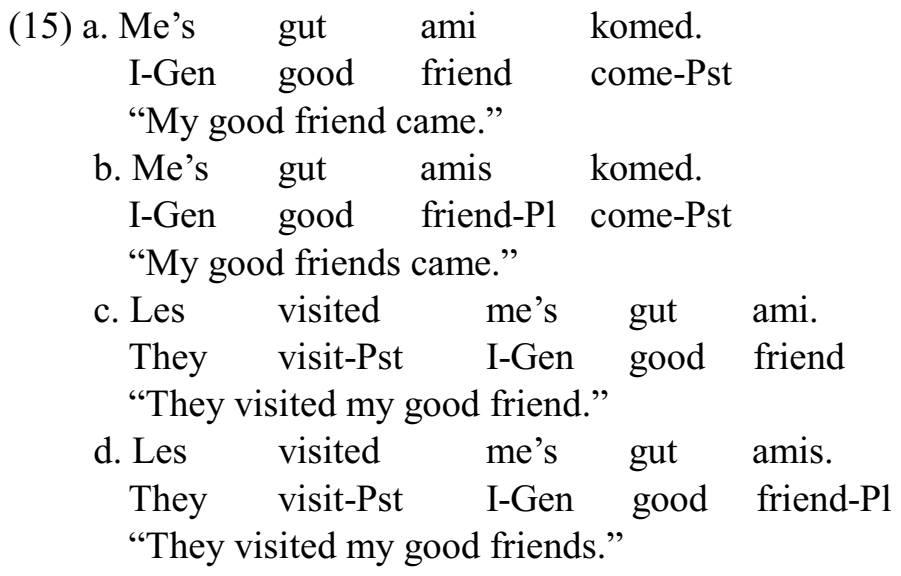

As shown in (15a) and (15c), the form of the NP me's gut ami is fixed irrespective of whether it is assigned nominative case or accusative case. The same applies to the form of the NP me's gut amis appearing in (15b) and (15d). In addition, regardless of the number of a noun in an NP, the form of a pronoun or an adjective that precedes the noun is fixed as illustrated in (15a-15b) and (15c-15d). Thus in Unish the agreement between a noun and the words preceding that noun in an NP does not occur.

Therefore, while the agreement in number and case occurs in an Esperanto NP through the use of several suffixes, that phenomenon does not occur in an Unish NP. Since there is no need to remember suffixes related to the agreement in an NP and attach them properly 
72 A Comparison of Unish Grammar with Esperanto

in Unish, it is easier to learn Unish NPs than Esperanto NPs.

\section{Summary and Concluding Remarks}

The comparison of several major parts in the grammar of Unish and Esperanto has shown that it is easier to learn Unish grammar than Esperanto one for various reasons.

First, the strict word order of a sentence in Unish makes it very simple to form an interrogative sentence in that neither a special word nor the movement of a wh-word is needed unlike Esperanto. Second, the use of only one suffix in forming a passive sentence in Unish is much more efficient than that of several suffixes in Esperanto. Third, the system of personal pronouns in Unish is more regular, more consistent, and smaller than that in Esperanto. Fourth, the use of just one relative pronoun in Unish makes it easier to form a relative clause than that of several relative pronouns in Esperanto. Fifth, the use of a meaningful content word as the subject of a sentence describing natural phenomena in Unish enables people to understand the sentence more quickly and clearly than the omission of the subject in Esperanto. Finally, the non-occurrence of agreement in Unish NPs makes it simpler to use NPs than the occurrence of agreement in the NPs of Esperanto.

Thanks to simplicity, regularity, consistency, and clarity of Unish grammar, people can acquire and use Unish more quickly and easily than Esperanto. In addition, both human translation and machine translation of an existing natural language into Unish can be carried out more efficiently and accurately than the translation of the language into Esperanto. Furthermore, Unish grammar is more flexible than the grammar of Esperanto since the former can be updated by linguists who conduct researches into Unish in accordance with the development of many natural languages used in the world. 


\section{References}

Choo, M. 1996. The Need for a Universal Language and Methods of Its Creation as Suggested by Hangul. Journal of Universal Language 1, 5-10.

Choo, M. 2001. The Need for "Unish", a Universal Language and the Principles of its Development. Journal of Universal Language 2, 3-14.

Choo, M., E. Kwak, D. Lee, H. Park, Y. Chung, J. Tak, T. Akiko, \& K. Bae. 2000. Seykyeye-uy Kaypal Panghyang [Directions for Developing Unish]. The Second Seminar on Unish in 2000. Seoul: Sejong University.

Chung, Y. 1996. An International Language for the World to Come. Journal of Universal Language 1, 56-70.

Chung, Y. 2001. Borrowing for a Universal Language. Journal of Universal Language 2, 24-33.

Comrie, B. 1996. Natural and Artificial International Languages: A Typologist's Assessment. Journal of Universal Language 1, 3555.

Diamond, J. 1996. Sejong's Achievement, as Viewed by an American Admirer. Journal of Universal Language 1, 11-19.

Esterhill, F. 2002. Interlanguage and 20th Century Scientific Communication. Journal of Universal Language 3, 17-33.

Hausser, R. 2002. Overcoming Language Barriers by Means of Computers. Journal of Universal Language 3, 35-54.

Kim, S. 2001. The Landscape of Languages at the Commencement of the 21st Century. Journal of Universal Language 2, 15-23.

Kim, S. \& S. Read. 1999. Like WTO, Why Not WCO for a Global Language? Journal of Sejong Languages 5, 83-93.

Large, A. 1996. The Prospects for an International Language. Journal of Universal Language 1, 20-34.

Large, A. 2002. The New Babel: Language Barriers on the World Wide Web. Journal of Universal Language 3, 77-95. 
74 A Comparison of Unish Grammar with Esperanto

Li, H. 1991. Esperanto-Korea Korea-Esperanto Vortaro [EsperantoKorean Korean-Esperanto Dictionary]. Seoul: Cayu Munko [Freedom Library].

Park, K. 1989. Kukceye Eyspeylanto Munpep [The Grammar of Esperanto, an International Language]. Seoul: Hanshin Publishing Company. 